Pakistan Journal of Social Research

ISSN 2710-3129 (P) 2710-3137 (O)

Vol. 3, No. 2, June 2021, pp. 138-145,doi.org/10.52567/pjsr.v3i02.215

www.pjsr.com.pk

\title{
NUTRITIONAL INADEQUACY ASSOCIATED WITH PHYSICAL GROWTH OF CHILDREN IN POOR URBAN AREAS
}

\author{
Muhammad Abdul Rahim \\ M-Phil Scholar. Department of Sociology. Government College University Faisalabad \\ Muhammad Atif \\ Research Officer, Department of Sociology. Government College University Faisalabad \\ Basharat Ali \\ Lecturer, Department of Sociology. Government College University Faisalabad \\ basharat492@gmail.com
}

\begin{abstract}
Malnutrition implies disparity of nutrients and energy in corporal status among children and grownups. Malnutrition abolition, in its all forms, is designated as second Sustainable Development Goal (SDGs) of United Nations (WHO, 2017). Occurrence of under nutrition (stunting, wasting and underweight) produces more chances of sickness and decease among children (UNICEF, 2019). A large number of reports discussed the aspects of malnutrition, guardians and caretakers, and applied various methods and data packages on different age classes, such as less than 5 years old, 5 to 10 years old, and 5 to 12 years old. In this study, researcher used the quantitative data techniques and the domain of present study consisted of high-risk union councils of Faisalabad. Four union councils; 209,210,211 and 212 were selected. Convenient Sampling Technique (CST) was used for the selection of respondents as well as localities for the present study. Sample size was 200 children from four union councils i.e. 50 children from each union council were selected. In this study, a significant $(\chi 2=11.21, p=.024)$ association among Mother's level of education and stunting among children, non-significant $(\chi 2=7.14, p=.129)$ association among Mother's level of education and control over wasting among children and a nonsignificant $\left(\chi^{2}=7.08, p=.132\right)$ association among Mother's level of education and weight for age of the children were considered.
\end{abstract}

\section{INTRODUCTION}

Malnutrition implies disparity of nutrients and energy in corporal status among children and grownups (WHO, 2018). Malnutrition abolition, in its all forms, is designated as second Sustainable Development Goal (SDGs) of United Nations (WHO, 2017). Occurrence of under nutrition (stunting, wasting and underweight) produces more chances of sickness and decease among children (UNICEF-2019). Over nutrition (obesity) specifies risk factors of non-communicable diseases (NCDs). Under nutrition, micronutrient-related malnutrition and over nutrition are all forms of malnourishment. Child malnutrition shows suffering in one or more than one forms as underweight, stunting and wasting (WHO, 2019). Stunting can be said as short height according to age, underweight as low weight according to age while low weight as compared to height identified as wasting (UNICEF, 2019).

\section{Malnutrition a global Problem}

Millions of masses are anguish with diverse types of malnutrition. Data reports depicted, 1.9 billion adults are over-weight/obese while 462 million have been affected due to under-weight. Among newborn, fiftytwo million of under-five years of age are suffering from wasting, where they have a less weight to height (WHO, 2019). Around one out of ten children are born with less birth weight, and in South Asia, it is one out of four, and nearly $45 \%$ of expiries among children under five are associated with under nutrition. These deaths often transpire in low and middle category income population in which early childhood obesity is also increasing at the same time. "Nutrition is the strong determinant of death and disease in the world. Economic, social and medical effects of malnutrition are solemn and lasting" (UNICEF, 2019). 
According to recent state of progression, malnutrition still incipient of severe community health and for extended time, predictable as consequential factor of poverty (UNICEF, 1998). Children belonging to poor socio-economic household status are 2.5 times more exposed of malnutrition as compared to middle or upper socioeconomic household status (Kikafunda, 1998). Higher degree of food insecurity is connected with households' lower socio-economic status because nutritious food diversity intake is meticulously associated with more income capacity (Asim, 2018). Households' social and economic status is most probably the face issues in physical growth due to consumption of low-grade food, state of illness, sewerage failure, dismal clean-living practices and scarcity of drinking water (UNICEF 2018). More years of schooling of mothers can diminish child malnutrition through raising responsiveness regarding follow up sanitation practices, healthy lifestyle and maximum resources allocation in child well-being services (Vella ,1992). Paternal schooling also vitally impacts the provision of family appropriate nutrition, housing, sanitation due to better income and suitable resource utilization (Mosiur, 2009). Higher socioeconomic status lowers the malnutrition rate among children in bottom lined developing states.

\section{Malnutrition in Pakistan}

Malnutrition is prominent in backward and poor countries, mainly in Africa and South Asia (UNICEF, 2016). In South Asia, the regions; India, Pakistan and Bangladesh, shows more occurrence of the problem. In Pakistan, poor nutrition is the foremost contributor of disease and demise among children less than five years of age, and state ranks at 22nd at global level for under-five child impermanence (Bhutta, 2013). The 2011 National Nutrition Survey described that $44 \%$ of under-five years' children in Pakistan were stunted, $15 \%$ were wasted \& $31 \%$ were underweight.

Pakistan's local conditions are poor in all provinces (such as Punjab, Sindh, Khyber Pakhtunkhwa, and Balochistan) in rural and urban areas and in gender perspectives etc. A large number of reports discussed the aspects of malnutrition, guardians and caretakers, and applied various methods and data packages to different age classes, such as less than 5 years old, 5 to 10 years old, and 5 to 12 years old. The study (Baig-Ansari, 2006) emphasized Sindh (rural and urban areas) to solve the problem of malnutrition in the province. The research of (Gul \& Kibria, 2013) emphasizes on different rural and urban areas of Khyber Pakhtunkhwa, while the research of (Mian, 2002) emphasizes the urban areas of Islamabad to emphasize malnutrition.

\section{OBJECTIVES}

- To examine the socio-economic conditions of target families in the study area, in particular, mother's educational level and its association with child health related issues.

- To explore the prevalence of malnutrition related detrimental effects like stunting, wasting and under-weight among 5 years' children, in the study area.

\section{REVIEW OF LITERATURE}

The significance to review the concerned materials cannot be ignored as it is the foundation to attain the scope of the subject to be designed to verify. According to Goode \& Hatt (1952), none of research projects can be commenced without this pilot orientation i.e. the knowledge of research that has already been completed in that particular field. It offers further clarity to the specific problem and at the same time, eliminates the option of unnecessary duplications of work. Further, potential information and way forward on research techniques may be gained from the reports of preceding research.

Singh (1992) stated that breast milk to feed a neonatal is significant in its association to control over the infectious diseases among newly born children. It also cleans the stomach of infant and keep the digestion system smooth.

Lee (1997) discussed that in many countries, mother's education has been shown as positively correlated with well-marked child survival and reduction of child nutritional deficiencies, even if other determinants have not changed. However, some studies have found that one indicator or both have weak or fictitious effects. Closest factors usually includes the improvement of the mother's educational level, 
child's balanced food and nutrient intake, better sanitary living and conditions, providing prenatal care and options for prescription care instead of outdated care, timely check for prenatal consultation, use of clinics that provide good baby care.

Anderson JW (1999) discussed that breastfeeding to control over micronutrient deficiency, is a vital source. And it contributes to speed up the health growing mechanism as it saves from respiratory and diarrheal infections.

Wagstaff, A. (2000) described that the health status of children born in poorer families is also the worst. For example, in the southeast and northeast of Brazil, between 1987 and 1992, the under-five mortality rate of the poorest third of the population was six times that of the richest families (113 vs. 19). In wealthy countries, the trend of reducing infant and under-five mortality rates is the fastest, because they spend more on child health for better growth, breastfeeding, and a clean life, and there is evidence from inspections that child mortality and the number of undernourished people is rapidly declining among the wealthy.

\section{METHODOLOGY}

The main purpose of this section is to explain the various tools and techniques used to collect, analyze, and interpret data related to the research questions being investigated. In this study, researcher used the quantitative data techniques and the universe of present study consisted of high-risk union councils of Faisalabad. Four union councils like 209,210,211 and 212 were selected. Sample may be defined as "The true representation of the universe, which had all the characteristics of the whole universe". Convenient Sampling Technique (CST) was used for the selection of respondents as well as localities for the present study. Sample size was 200 children from four union councils i.e. 50 children from each union council were selected. The physical measurements of target children were taken according to the anthropometric guidelines. SPSS statistical software was used for statistical analysis to generalize the inferences. Then a bivariate analysis of the main variables: stunting, underweight, and wasting was applied.

\section{RESULTS AND DISCUSSION}

It is imperative to carry out detailed survey in order to find out the facts and figures related to any social problem. Analysis of data leads to the inferences without which no study could be successful. Generalization and conclusions are drawn on the basis of characteristics and attitude of the respondents.

The study demonstrates that $14 \%$ respondents were having the nuclear family system, while $32 \%$ respondents belonged to the joint family system. Here the significant figure of $54 \%$ shows the respondents carrying the extended family system as larger tendency. Study also portrays that $24 \%$ respondents are associated with the family set up having up to 8 members. And $44.5 \%$ respondents were having 9 to 12 members in their family set up. 31.5\% respondents were having more than 12 members in their set up. The analysis shows that $15.5 \%$ respondents' families were having 1 child up to 5 years, $39.5 \%$ respondents' families were having 2 children up to 5 years and $29.5 \%$ respondents' families were having 3 children up to 5 years, $6.5 \%$ respondents' families were having four children up to 5 years and $9.0 \%$ respondents' families were having five and above children up to 5 years.

Data highlights that $20 \%$ respondents' families were having laboring profession for their family livelihood, while $18 \%$ respondents' families were doing the daily wages as their economic activity and everyday earnings. Similarly, 25.5\% respondents' families were having contract jobs in private companies, factories, offices. A very few percentage of 5.5\% had the permanent jobs. $27 \%$ respondents' families were having their own business i.e. cloth shop, small scale factory, general store etc. And only $2 \%$ respondents' families had their family heads abroad, earning foreign remittances for their family survival. Analysis indicates that $13.5 \%$ respondents' families had monthly income up to Rs. / 15000 . $63.5 \%$ respondent families had the income group of 15000 to 25000 per month to meet their family needs for food, clothing and others. And 23\% respondents' families were having more than 25000 rupees to meet their monthly needs.

The study points out that $27 \%$ mothers were working in the study area, while $73 \%$ were not engaged in any income generating activities and perform only household chores. 
Research depicts that out of working women; only $07 \%$ are related to teaching profession at their mohala level. Only 10\% women are working as domestic labor in rich houses of surrounded colonies. $06 \%$ working women are related with stitching/sewing of the clothes. Only $04 \%$ are working as beauticians at their local level. The study shows that $17 \%$ women out of all these low-scaled working class are earning only up to 10,000/-rupees monthly and $7.5 \%$ women are earning up to 15,000 rupees monthly while only $2.5 \%$ women are earning more than 15,000 rupees monthly.

\section{Univariate Analysis}

Table 1: Percentage Distribution of Mothers' Educational Level.

\begin{tabular}{|l|c|c|}
\hline Educational level & f & \% \\
\hline Illiterate & 41 & 20.5 \\
\hline Primary & 41 & 20.5 \\
\hline Middle & 31 & 15.5 \\
\hline Matric & 47 & 23.5 \\
\hline Intermediate & 15 & 7.5 \\
\hline Graduation and above & 25 & 12.5 \\
\hline Total & 200 & 100.0 \\
\hline
\end{tabular}

Table 1 described that the respondents' mother educational level in the study area shows $20.5 \%$ as illiterate, while $20.5 \%$ respondents' mothers had the primary level of education. $15.5 \%$ respondents' mothers had middle level of education. $23.5 \%$ respondents' mothers had matriculation level of education, $7.5 \%$ respondents' mothers had intermediate level of education, while $12.5 \%$ respondents' mothers' level of education was graduation and above.

The household related chores of life, relating to child bearing and rearing, cooking food, clothing washing, flooring, social responsibilities, hospitalities of guests and patient care are usually performed by women in our society. The ability, capacity and intellect level of woman plays a vital role in rearing of child; therefore, the development of food related better habits is managed by educated women. They have rational approach to maintain balance in the daily diet of their children and the children tend to develop and gain good health.

Table 2: Percentage Distribution of target Children, Underweight, Stunting, Wasting

\begin{tabular}{|l|c|c|}
\hline Response & f & \% \\
\hline Underweight (weight for age) & 72 & 36.0 \\
\hline Normal & 128 & 64.0 \\
\hline Total & 200 & 100.0 \\
\hline Stunting (height for age) & 62 & 31.0 \\
\hline Normal & 138 & 69.0 \\
\hline Total & 200 & 100.0 \\
\hline Wasting (weight for height) & 43 & 21.5 \\
\hline Normal & 157 & 78.5 \\
\hline Total & 200 & 100.0 \\
\hline
\end{tabular}

Table 2 indicates that $36 \%$ children are facing the problem of underweight, out of 200 children, $64 \%$ are normal by weight according to their age structure. $31 \%$ children are stunted in the study area as $69 \%$ are normal by the growth according to their age structure and $21.5 \%$ children are facing the problem of wasting in their age structure as $78.5 \%$ are normal. The study related to malnutrition proves the prevalence of malnutrition among children health either they are under weight, short heighted or underweight in vivid manner. 


\section{BI-VARIATE ANALYSIS}

Hypothesis 1: Mother's level of education will be influencing the control over stunting among children

Table 3: Relationship between Mother's level of education and stunting among children

\begin{tabular}{|l|c|c|c|}
\hline \multirow{2}{*}{$\begin{array}{l}\text { Mother's education } \\
\text { level }\end{array}$} & \multicolumn{2}{|c|}{ HAZ-NCHS } & \multirow{2}{*}{ Total } \\
\cline { 2 - 4 } & Stunting & Normal & \\
\hline \multirow{3}{*}{ Primarerate } & 18 & 23 & 41 \\
\hline \multirow{2}{*}{ Middle } & $43.9 \%$ & $56.1 \%$ & $100.0 \%$ \\
\cline { 2 - 4 } & 18 & 23 & 41 \\
\hline \multirow{3}{*}{ Matric } & $43.9 \%$ & $56.1 \%$ & $100.0 \%$ \\
\hline \multirow{2}{*}{$\begin{array}{l}\text { Intermediate and } \\
\text { above }\end{array}$} & 8 & 23 & 31 \\
\hline \multirow{2}{*}{ Total } & $9.8 \%$ & $74.2 \%$ & $100.0 \%$ \\
\cline { 2 - 4 } & $9.1 \%$ & 38 & 47 \\
\hline
\end{tabular}

Chi-square $=11.21 \quad$ p-value $=.024 *$

Gamma $=.316 \quad$ P-value $=.003 * *$

$*$ = Significant

** = Highly significant

Above table 3 displays a significant $(\chi 2=11.21, \mathrm{p}=.024)$ association among mother's level of education and stunting among children. Gamma statistic $(\lambda=0.316, p=.003)$ showed a significant and positive relation among the variables. It tells that education of mother had positive impact on the stunting of children. It is clear from the above findings, around $44 \%$ children of illiterate and primary passed mothers were stunting. On the other hand, a majority (77.5\%) highly qualified mothers (intermediate and above) had normal height for age of their children. So, the hypothesis "Mother's level of education will be influence on the control over stunting among children" is accepted.

Hypothesis 2: Mother's level of education will be influence on the control over wasting among children

Table 4: Relationship between Mother's level of education and wasting among children

\begin{tabular}{|l|c|c|c|}
\hline \multirow{2}{*}{$\begin{array}{l}\text { Mother's education } \\
\text { level }\end{array}$} & \multicolumn{2}{|c|}{ WHZ-NCHS } & \multirow{2}{*}{ Total } \\
\cline { 2 - 4 } & Wasting & Normal & \multicolumn{1}{|c|}{} \\
\cline { 2 - 4 } & 8 & 33 & $100.0 \%$ \\
\hline \multirow{2}{*}{ Primary } & $19.5 \%$ & $80.5 \%$ & 41 \\
\cline { 2 - 4 } & 12 & 29 & $100.0 \%$ \\
\hline \multirow{2}{*}{ Middle } & $29.3 \%$ & $70.7 \%$ & 31 \\
\cline { 2 - 4 } & 5 & 26 & $100.0 \%$ \\
\hline \multirow{2}{*}{ Matric } & $16.1 \%$ & $83.9 \%$ & 47 \\
\hline \multirow{2}{*}{$\begin{array}{l}\text { Intermediate and } \\
\text { above }\end{array}$} & 14 & 33 & $400.0 \%$ \\
\hline \multirow{2}{*}{ Total } & $29.8 \%$ & $70.2 \%$ & $100.0 \%$ \\
\cline { 2 - 4 } & 4 & 36 & 200 \\
\cline { 2 - 4 } & $10.0 \%$ & $90.0 \%$ & $100.0 \%$ \\
\hline
\end{tabular}


Chi-square $=7.14 \quad$ p-value $=.129^{\mathrm{NS}}$

Gamma $=.103 \quad \mathrm{P}$-value $=.362^{\mathrm{NS}}$

NS $=$ Non-Significant

Above table 4 displays a non-significant $(\chi 2=7.14, p=.129)$ association between mother's level of education and control over wasting among children. Gamma statistic $(\lambda=0.103, p=.362)$ also showed a non-significant, while positive relation among the variables. It tells that education of mother had no relation with wasting among children. Therefore, the hypothesis "Mother's level of education will be influencing the control over wasting among children" is rejected.

Hypothesis 3: Mother's level of education will be influencing the control over underweight phenomenon of the children

Table 5: Relationship between Mother's level of education and weight according to age of the children

\begin{tabular}{|l|c|c|c|}
\hline \multirow{2}{*}{$\begin{array}{l}\text { Mother's education } \\
\text { level }\end{array}$} & \multicolumn{2}{|c|}{ WAZ-NCHS } & \multirow{2}{*}{ Total } \\
\cline { 2 - 4 } & Underweight & Normal & \\
\cline { 2 - 4 } & 17 & 24 & 41 \\
\hline \multirow{3}{*}{ Primary } & $41.5 \%$ & $58.5 \%$ & 41 \\
\hline \multirow{2}{*}{ Middle } & 18 & 23 & $100.0 \%$ \\
\cline { 2 - 4 } & $43.9 \%$ & $56.1 \%$ & 31 \\
\hline \multirow{3}{*}{ Matric } & 8 & 23 & $100.0 \%$ \\
\hline \multirow{2}{*}{$\begin{array}{l}\text { Intermediate and } \\
\text { above }\end{array}$} & $25.8 \%$ & $74.2 \%$ & 47 \\
\hline Total & 20 & 27 & $100.0 \%$ \\
\cline { 2 - 4 } & $22.6 \%$ & $57.4 \%$ & 40 \\
\cline { 2 - 4 } & 9 & 31 & $100.0 \%$ \\
\hline
\end{tabular}

Chi-square $=7.08 \quad$ p-value $=.132^{\mathrm{NS}}$

Gamma $=.166 \quad \mathrm{P}$-value $=.102^{\mathrm{NS}}$

NS $=$ Non-Significant

Above table 5 displays a non-significant $(\chi 2=7.08, \mathrm{p}=.132)$ association between mother's level of education and weight according to age of the children. Gamma statistic $(\lambda=0.166, p=.102)$ also showed a non-significant, while positive relation among the variables. It tells that education of mother had no relation with weight according to age of the children. So, the hypothesis "Mother's level of education will be influencing the control over weight according to age of the children" is rejected.

\section{CONCLUSION}

The study was launched in big metropolitan city of Faisalabad, covering huge population. The population of the city is migrated from all areas of Punjab in search of economic opportunities for their survival. Target population was residing in low-income municipalities, peripheries, katchi abadies/slums where the issues of public health exist. The standard of civic services is again a challenge for inhabitants and district administrations. In spite of all kinds of deprivations, the next generation is destined to make the life better. The children were the center of this academic effort to highlight their confronted problem related to their health. The study will be helpful at policy level for implementing some supportive actions for their betterment and upbringing. 
Data tells that education of mother had positive impact on the control over stunting of children. Around $44 \%$ children of illiterate and primary passed mothers were stunting. On the other hand, a majority (77.5\%) highly qualified mothers (intermediate and above) had children with normal height according to their ages. Therefore, the hypothesis "Mother's level of education will be influencing the control over stunting among children" is accepted.

Data indicates that $21.5 \%$ children out of 200 children are facing the problem of wasting. While out of 200 children $78.5 \%$ are normal by weight according to their height.

Data displays a non-significant $\left(\chi^{2}=7.08, \mathrm{p}=.132\right)$ association between Mother's level of education and weight according to the age of the children. Gamma statistic $(\lambda=0.166, p=.102)$ also showed a non-significant, while positive relation among the variables. It tells that education of mother had no relation with weight according to the age of the children. So, the hypothesis "Mother's level of education will be influencing the control over weight for age of the children" is rejected.

\section{REFERENCE}

Anderson, J. W, Johnstone, B .M, Remley, D. T. (1999). Breast-feeding and cognitive development: a meta-analysis. Am J Clin Nutr, 70, 525-535.

Asim, M., Nawaz, Y. (2018). Child malnutrition in Pakistan: evidence from literature. Children, 5(5), 60

Baig-Ansari, N., Rahbar, M. H., Bhutta, Z. A., \& Badruddin, S. H. (2006). Child's gender and household food insecurity are associated with stunting among young Pakistani children residing in urban squatter settlements. Food and nutrition bulletin, 27(2), 114-127.

Bhutta, Z. A., Hafeez, A., Rizvi, A., Ali, N., Khan, A., Ahmad, F., \& Jafarey, S. N. (2013). Reproductive, maternal, newborn, and child health in Pakistan: challenges and opportunities. The Lancet, 381(9884), 2207-2218.

Demissie, S., Worku, A. (2013). Magnitude and factors associated with malnutrition in children 659 months of age in pastoral community of Dollo Ado district, Somali region, Ethiopia. Sci J Public Health, 1(4), 175-183

Goode, W. J. \& P. K, Hatt. (1952). Methods in Social Research, U.S.A McGraw Hill Book Co., Inc., New York.

Gul, R., \& Kibria, Z. (2013). Prevalence and Predeterminants of Malnutrition In Children Under 3 Years Of Age In The Two Rural Communities Of Peshawar. Khyber Medical University Journal, 5(4).

Kikafunda, J. K, Walker, A.F, Collett, D., Tumwine, J. K. (1998). Risk factors for early childhood malnutrition in Uganda. Pediatrics, 102(4), e45-e45

Lee L-F, Rosenzweig M, Pitt M. (1997). The effects of improved nutrition, sanitation, and water quality on child health in high-mortality populations. J Econometrics, 77, 209-235.

Mian, R. M., Ali, M., Ferroni, P. A., \& Underwood, P. (2002). The nutritional status of school-aged children in an urban squatter settlement in Pakistan. Pak J Nutr, 1(3), 121-123

Mosiur, R., Golam, M., \& Nasrin, S. O. (2009). Nutritional status among children aged 24-59 months in rural Bangladesh: an assessment measured by BMI index. Internet J Biol Anthropol, 3(1).

Singh, K. (1992). The effect of colostrum on infant mortality: urban rural differentials. Health and Population, 15, 94-100.

Wagstaff, A. (2000). Socioeconomic inequalities in child mortality: comparisons across nine developing countries. Bulletin of the World Health Organization, 78, 19-29.

UNICEF. (1998). Malnutrition: causes, consequences and solution. The state of the world's children.

Bhutta, Z. A. (2016). The state of the World's children 2016: a fair chance for every child, United Nations, New York, https://doi.org/10.18356/4fb40cfa-en. 14.

UNICEF. (2018). National Nutritional Survey Key Findings Report, 2018. United Nations International Children Emergency Funds New York.

UNICEF. (2019). Country wise over review Malnutrition burden in Pakistan, United Nations International Children Emergency Fund, New York, USA.

United Nations. (2016). Sustainable development goals report. Retrieved from https://www.unep.org/environmentunderreview/sites/unep.org.environmentunderreview/file s/documents/The\%20Sustainable\%20Development\%20Goals\%20Report\%202016_0.pdf 
Vella, V., Tomkins, A., Borghesi, A., Migliori, G.B., Adriko, B.C., \& Crevatin, E. (1992). Determinants of child nutrition and mortality in north-west Uganda. Bull World Health Organ, 70(5), 637

World Health Organization. (2019). Levels and trends in child malnutrition key findings edition, 2019. World Health Organization (WHO). United Nations New York. Retrieved from: https://www.who.int/nutgrowthdb/jme-2019-key-findings.pdf?ua=1

World Health Organization. (2017). Levels and trends in child malnutrition UNICEF - WHO - World Bank Group joint child malnutrition estimates, Key findings of the 2017. 